\title{
Amended patent legislation still flawed
}

Amendments to federal patent legislation improve the bill but still restrict the generic drugs it would make available to treat HIV/AIDS and other illnesses in the developing world, says Médecins Sans Frontières.

Bill C-9, which amends the Canada Patent Act, is intended to allow generic drug manufacturers to export patented drugs to the developing world making it cheaper for poor countries to buy essential medicines for their citizens. The legislation is the Liberal government's showpiece response to the AIDS epidemic, particularly in Africa.

But nongovernmental orga- nizations have been lobbying to strengthen the proposed legislation. Initially, the bill contained loopholes that allowed patent holders the "right of first refusal" to match any agreement generic companies had negotiated with a develop- ing nation. That right has now been eliminated.

"The government has moved a long way," David Morley, MSF's executive director, told a news conference on Parliament Hill April 20.

But the legislation still maintains a narrow list of medications that generic companies can manufacture and export, adds wording that could invite litigation from patent holders, and restricts the number of countries that could benefit from the legislation.

"The list [of drugs] is not necessary and it should be removed," Morley says.

For example, tenofovir - a common antiretroviral that MSF doctors are using to treat HIV/AIDS - is not on the list. Nifurtimox, used to treat sleeping sickness, is also absent. Adding a new drug to the list involves a "cumbersome and bureaucratic" process, say Morley

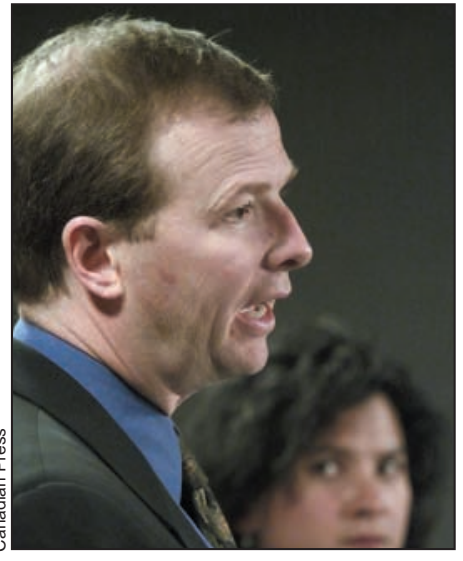

David Morley, executive director of Médecins Sans Frontières, speaks out on changes to the Canada Patent Act.

and the other nongovernmental agencies.

They hope to influence more changes to the bill, which is before the Standing Committee on Industry. A final vote is expected this spring. - Laura Eggertson, CMAJ

\section{Research Controversy}

\section{Link between MMR and autism dispelled}

There is no link between the measles, mumps and rubella (MMR) vaccine and autism, according to 10 of the authors of a study that sparked intense controversy about the vaccine's safety in the UK in 1998.

In the study (Lancet 1998;351: 637-41) the authors made it clear that they had not proven a link between MMR and autism, but they did say such a link was possible. This interpretation and subsequent publicity led to a collapse in confidence in the MMR and left the UK and other countries vulnerable to a major measles outô break (CMAf 2003;169[11]:1200).

Writing in the Lancet in March (2004;363:750) 10 of the 13 authors retracted that interpretation. The lead author, Dr. Andrew Wakefield, did not sign the retraction. At the time of the 1998 publication, he was being paid to conduct research for a group of parents of autistic children who were interested in suing for damages they believed were caused by the MMR vaccine. The editors of the Lancet stated that they "regret" this potential conflict wasn't disclosed at the time.

The formal retraction follows efforts by some of the authors to distance themselves from ongoing media speculation about the link between autism and MMR. Writing in the Lancet in November last year, one of them, gastronenterologist Simon Murch, stated: "There is now unequivocal evidence that MMR is not a risk factor for autism - this statement is not spin or medical conspiracy, but reflects an unprecedented volume of medical study on a worldwide basis."

Lancet Editor Richard Horton says the UK must now learn from the extraordinary public row that led to the fall in vaccination rates. He argues the UK's Consumers' Association and its Drugs and Therapeutics Bulletin (DTB) are uniquely placed to make sense of the debate for the public. He says they should have a pivotal role in a future "collaborative consultation" on learning the lessons from the debacle.

In a review of the evidence last year, DTB advised UK doctors that the MMR vaccine is highly effective and that there is no evidence of a link with autism. $D T B$ Managing Editor told $C M A 7$ that the MMR issue typifies $D T B$ 's unique role identified by the Lancet. "We're focused on the fact that doctors in surgeries need to make decisions. We don't allow ourselves the luxury of sitting on the fence." - Colin Meek, Wester Ross, Scotland 